IP Periodica Polytechnica Civil Engineering

59(1), pp. 85, 94,2015

DOI: $10.3311 / P P c i .2103$

Creative Commons Attribution $\odot$

RESEARCH ARTICLE

\section{Effect of Aircraft Wheel Load and Configuration on Runway Damages}

\author{
Gholam Ali Shafabakhsh, Ehsan Kashi
}

Received 11-05-2013, revised 25-07-2014, accepted 26-11-2014

\begin{abstract}
According to the growing trend of aircraft industry, a variety of different aircrafts exist in the market which varies in types of use, geometric shape of the wheels and main gear configuration. In this paper, we used LEDFAA software for research about effect of Airbus and Boeing gear configuration on runways rigid and flexible pavement. Cumulative Damage Factor (CDF has been calculated for Airbus and Boeing aircrafts in this research as well. Also for validation of this numerical study, CDF curves were drawn by using FAARFIELD software. The effect of gear configuration and lateral distance from centerline of runway were evaluated and critical zones of runway were detected. This paper confirms AC150/5320-16 about B-777; that canceled airport pavement design in mixed traffic for the Boeing 777 Airplane. In other hand, among Airbus group aircrafts A - 340-500/600 have the most damage factor contribution on flexible and rigid pavements.
\end{abstract}

\section{Keywords}

LED method · Gear configuration · Airfield pavement damage $\cdot$ Individual wheel load

\section{Gholam Ali Shafabakhsh}

Faculty of Civil Engineering, Semnan University, Zip Code: 35131-19111, Semnan, I. R. of Iran

e-mail: shafabakhsh@semnan.ac.ir

\section{Ehsan Kashi}

Faculty of Civil Engineering, Semnan University, Zip Code: 35131-19111, Semnan, I. R. of Iran

\section{Introduction}

Nowadays many aircrafts with different weight and gear configuration are landing on airport runways. It is clear that this difference in airplanes causes different quantity of damage on the rigid and flexible pavements. In industrial countries, the Airport Pavement Management System (APMS) has played a main role to reduce pavement damage and expense of maintenance and repairing process [1]. In this case, Federal Aviation Administration (FAA) studies on experimental models with full scale testing focusing on the result of making 2D and 3D models by finite element method that prepared for using aircraft next generations [2-4]. In this research, LEDFAA is used for evaluation of gear configuration effects on rigid and flexible pavement damage by FAA method, which is based on Layered Elastic Design method. This software made by FAA and in this numerical study its 1.3 version (June 2004) was used. The LEDFAA is capable to design and analyze rigid and flexible pavement and composite pavement by FAA method [5]. This software has several capabilities to analyze the cumulative damage factor for any aircraft in the pavement system. Also FAA Rigid and Flexible Iterative Elastic Layered Design software (FAARFIELD) is used for detecting critical zones of runway and evaluating the effect of gear configuration and lateral distance from centerline of runway [6]. This software is a computer program for airport pavement thickness design. It implements both layered elastic based and threedimensional finite element-based design procedures developed by the FAA for new and overlay design of flexible and rigid pavements. This paper confirms AC150/5320 - 16 [7] about the effect of B-777 in mixed traffic by comparing results from these softwares.

\section{Research History}

Landing gear configuration and aircraft gross weight are an integral part of airfield pavement design and are often used to characterize pavement strength. Historically, most aircraft used relatively simple gear geometries such as a single wheel per strut or two wheels side by side on a landing strut. As aircraft became larger and heavier, they required additional wheels to prevent individual wheel loads from introducing excessively high stresses 
into the pavement structure. For economy and efficiency reasons, aircraft manufacturers added more wheels per landing strut whenever possible. This often led to groups of wheels placed side-by-side and in tandem configurations. There are many researches about runway pavement damages and effecting different aircrafts on it. FAA constructed National Airport Pavement Test Facility (NAPTF) where the primary objective was to develop new airport pavement design procedures for the next generation aircraft configured with complex and large loading gears [8.9]. Thompson and Garg (1999) introduced an "Engineering Approach" to determine critical pavement responses under typical multiple wheel aircraft gear loadings and evaluate wheel load interaction effects on the flexible pavement responses [8]. Also in 2004, Erol Tutumluer and Tai Kim, by using different tests for studying permanent deformation behavior in airport pavement on the A380, B777-300, B747 and other military aircrafts showed that B777-300 and A380 had most effect to the amount of rutting in flexible pavements [10]. In 2006, Rodney N.joel, a member of FAA's airport engineering board, used FAA's different software such as LEDFAA and FEDFAA. He recognized the following points by using old airport analysis and planning in the world. So he developed it for aircraft next generations [11]. Rodney N.joel indicated:

- We should have predicting about airport pavements in the next years by evaluating widen aircrafts in the next generations and their damages by using 2D, 3D finite element software. As a result, the next generations should be bigger and widen.

- With widening aircraft next generations, we should take more care of the number and arrangement wheels and producers should choose the best kind of wheel's geometric arrangement.

Al-Qadi and Wang in 2010 [12], evaluated pavement damage due to new tire designs. They indicated that the wide-base tire causes greater fatigue damage and subgrade rutting than the conventional dual-tire assembly does when carrying the same load. Adil Godiwalla and Dev R.Pokhrel in 2011, studied about airport pavement software such as FAARFIELD and LEDFAA1.3. They indicated effect of gear position and critical stress location. They showed FAARFIELD is capable of handling New Large Aircrafts (NLA) with complex landing gear configuration including B-777, Airbus A380 and An-225 [13]. In 2011, Mojarrad $\mathrm{H}$, in his $\mathrm{PhD}$ thesis indicated that, Aircrafts would apply significant shear loads on airport pavements. In his study, lower allowable number of load repetitions was observed for the pavement in the presence of shear loads. Although the observation was captured more clearly for circular tire imprint, but in case of full depth asphalt pavement section, presence of shear loads impacted the pavement response for both circular and elliptical tire imprints [14]. Shafabakhsh and Kashi in 2012 conducted a numerical study on the runway pavement [15]. This research showed that aircraft gear configuration is an effective factor in the rate of pavement damages. Also among all of the Airbus aircrafts, A340-500/600 has more weight distributed to each wheel, the A340 - 500/600 has a dual-tandem belly gear instead of a dual-wheel belly gear, this aircraft's arrangement is regulated than other aircraft in Airbus group, and gross weight load is distributed upon a higher level of the pavement.

\section{Layered Elastic Model Assumptions and Inputs}

A layered elastic model can compute stresses, strains and deflections at any point in a pavement structure resulting from the application of a surface load. Layered elastic models assume that each pavement structural layer is homogeneous, isotropic, and linearly elastic. In other words, it is the same everywhere and will rebound to its original form once the load is removed. The origin of layered elastic theory is credited to V.J. Boussinesq who published his classic work in 1885 . In classical mechanics, solutions to various solid mechanics problems have very well been established. The most famous one is the Boussinesq solution for the case of concentrated vertical load acting on the surface of a semi-infinite body. However, in engineering problems like foundation, road or airport pavement design, solutions to a multi-layered system are required. Elastic layered analyses have been easily implemented and widely accepted. Although elastic layered programs have several advantages, they can usually not give accurate pavement responses. First of all, these methods assume that all layers are linear elastic but this assumption makes it difficult to analyze layered system consisting of nonlinear base/subbase and subgrade soil materials. Secondly, all wheel loads applied on top of the surface layer have to be axisymmetric, which is not true for actual wheel loads. At last, elastic layered programs assume isotropic material property that is not realistic for most geomaterials, especially not for unbound aggregate materials [16, 17]. Limitations like these are hard to show that realistic pavement responses can be predicted using elastic layered programs. These difficulties can be overcome by using the finite element method. On the other hand one of the limitations of LEDFAA for rigid pavements is the lack of a direct slab edge stress calculation. Slab interior stress is calculated first, and then converted into edge stress using transformation functions developed for specific aircraft. Fig. 1 shows how these inputs relate to a layered elastic model of a pavement system.

\section{Cumulative Damage Factor for flexible and Rigid Pavement}

Cumulative Damage Factor $(C D F)$ is the amount of the structural fatigue life of a pavement which has been used up. It is expressed as the ratio of applied load repetitions to allowable load repetitions to failure. When $C D F=1$, the pavement will have used up all of its fatigue life. When $C D F<1$, the pavement will have some life remaining, and the value of the $C D F$ will give the fraction of the life used. When $C D F>1$, all fatigue life will have been used up and the pavement will have failed [6]. 


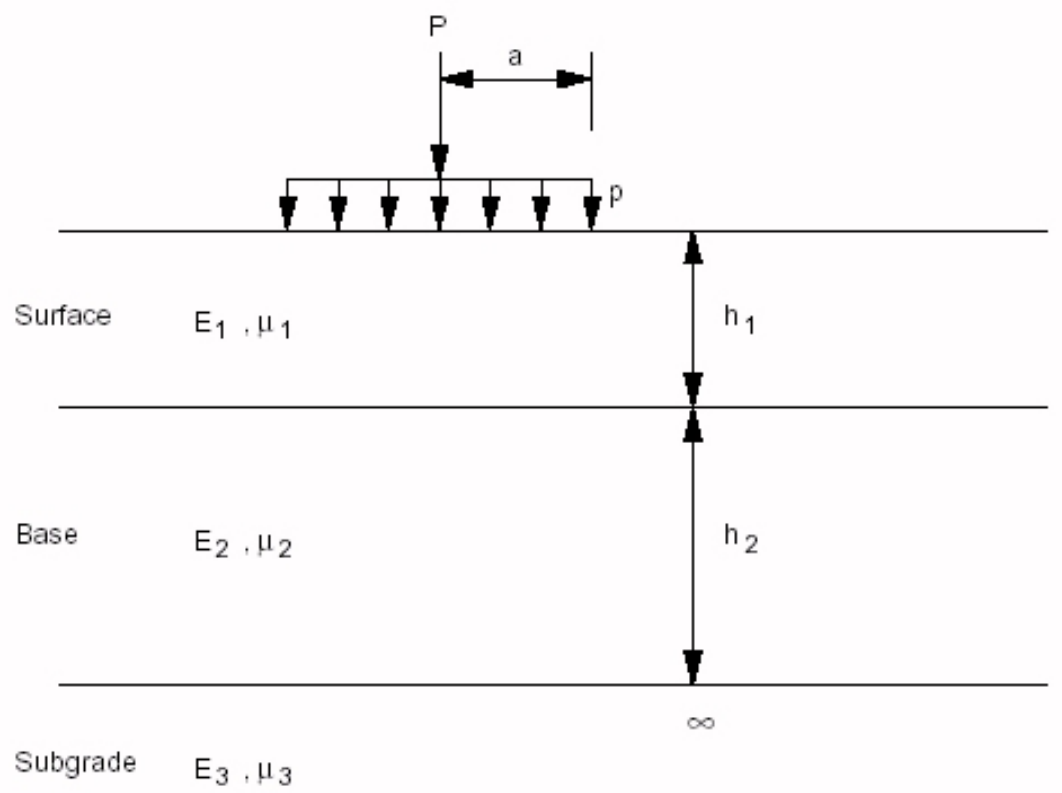

Fig. 1. Layered elastic characteristics

For flexible design, the thickness of the layer top of the subgrade is adjusted to make the subgrade $C D F$ approximately equal to one. The current error control is that the design will terminate when $C D F$ is in the range 0.995 to 1.005 . If the layer next to the subgrade becomes thinner than its specified minimum thickness, the thickness of the layer above is halved, or set at its minimum thickness, and the procedure continues. If the $C D F$ is less than one with both of the adjusted layers at their minimum thicknesses, the $C D F$ is displayed and the design terminates. This procedure is not intended to optimize a design. It is intended only to protect from inappropriate input data. Viscoelastic effects are done in other research and we only evaluated flexible pavement based on elastic theory [18].

The failure model used to find the number of coverages to failure for a given vertical strain at the top of the subgrade is shown in the following equations [19]:

$$
\begin{gathered}
C=\left(\frac{0.004}{\varepsilon_{v}}\right)^{8.1} \text { when } C \leq 12,100 \\
C=\left(\frac{0.002428}{\varepsilon_{v}}\right)^{14.21} \text { when } C>12,100
\end{gathered}
$$

Where:
$C$ number of coverages to failure
$\varepsilon_{v} \quad$ vertical strain at the top of the subgrade

Rigid design is the same as flexible design except that $C D F$ is calculated using the horizontal edge stress at the bottom of the PCC layer. Coverages Parameter in rigid pavements is considered as the number of frequency of maximum tensional stresses which happen under the rigid slab and during the lifetime of designing. The basic equation used to find the number of coverages to failure $(C)$ for given concrete strength $(R)$ and working stress for design $(\delta)$ is shown in the following [20]:

$$
S C I=\frac{\frac{R}{\delta}-0.2967-(0.3881+0.000039 \times S C I) \log C}{0.002269}
$$

Where $R$ is concrete flexural strength (MPa), $\sigma$ is the computed concrete tensile strength (MPa), SCI (Structural Condition Index) is defined as the structural component of PCI. This parameter is range of zero to 100 . The suggested amount is 80 according to the $F A A$ standard [21]. In these definitions, failure means defect in a particular structural failure mode according to the assumptions and definitions on which the design procedures are based. A value of $C D F$ greater than one does not necessarily mean that the pavement will no longer support traffic, but that it will have failed according to the definition of failure used in the design procedure, and within the constraints of uncertainties in material property assumptions, etc. Nevertheless, the thickness design is based on the assumption that failure occurs when $C D F=1$. In this section, first we evaluate the contribution of $C D F$ for aircrafts in Airbus and Boeing groups. Then we will have a case study in a sample airport with mixed traffic and similar assumptions. In this case, we will first design airport flexible and rigid pavement with similar assumptions for all of the Airbus and Boeing, then the results and diagrams about $C D F$ contribution for aircrafts will be shown in the next sections.

\section{CDF Contribution for Sample Airport with Mixed Traf- fic by LEDFAA software}

As shown in section 4 about $C D F$ rate calculated by LEDFAA and FAARFIELD softwares, in this section, with using results of many separate Numerical studies [15], finally among 11 models of Airbus and 16 model of Boeing in software, 15 models which had a highest $C D F$ rate are chosen for mixed traffic in sample airport (sample airport only was supposed for numeri- 
cal studies). Also annual departure in first year is assumed 1200, and percent annual growth is assumed 5\%. Traffic data and other design assumptions for sample airport are shown in Table 1 .

Design assumptions about rigid and flexible pavement, layers material and structural data are shown in Table 2

Where:

PCC S urface Portland cement concrete surface

$P$ - $304 C T B$ Cement treated base course

$P$ - $209 \mathrm{Cr} \mathrm{Ag}$ Crushed aggregate subbase course

$P$ - 401 AC Asphalt concrete surface.

$P$ - 401 St Stabilized bases for flexible pavement

$k \quad$ Modulus of subgrade reaction.

$R \quad$ Portland cement concrete flexural strength

$C B R$ California bearing ratio

For flexible example, a base thickness of $203.2 \mathrm{~mm}$ was finally selected. After the final design run, the subbase thickness of $459.7 \mathrm{~mm}$ gave a total pavement thickness of 789.9 inches. These results show that for sample airfield with this mixed traffic, the flexible pavement thickness is more than rigid pavement. After the design process for 15 aircraft in sample aircraft mixed traffic, the results are shown in Fig. 2 which is a calculation of $C D F$ rate in rigid and flexible pavements.

As shown in Fig. 2, A340-500/600 has 25\% and B777$300 \mathrm{ER}$ has $19 \%$ of the total $C D F$ in rigid pavement. Also for flexible pavement B777-300 ER has the highest rates with $42 \%$ of total $C D F$. We found that between all of the Airbus and Boeing aircrafts, B777-300 ER has the highest $C D F$ rate in flexible pavement because this aircraft have special gear configuration [22]. In the next section we will study the reasons. A further distinction between the conventional FAA and LEDFAA's method of treating traffic is that the pass-to-coverage ratios are different. FAA's are based on the overlap of tire contact areas on the pavement surface whereas LEDFAA considers the overlapping effects of a wider 'effective' tire width at subgrade level and also considers the depth to subgrade relative to axle spacing when deciding the number of effective strain repetitions. However, because LEDFAA computations are framed in terms of aircraft departures rather than coverage, the pass-to-coverage ratios are not accessible to the user. Thus LEDFAA processes the traffic in fundamentally different ways to those used by the FAA conventional design method. As stated earlier it is conditioned to produce similar pavement thicknesses for typical traffic mixes. Consequently the use of LEDFAA for single aircraft assessments is problematic and may produce conservative pavement thicknesses, as discussed in the LEDFAA manual.

\section{Evaluation of aircraft individual wheel load}

Aircraft gear configuration is an effective factor in the rate of pavement damages on airfield. Weighty aircrafts gear arrangement leads to distribution upon a higher level of subgrade. The results show that whatever wheels arrangement is wider, the $C D F$ for aircraft is lesser, and vice versa. As shown in Fig. 2 there is little difference between rigid and flexible pavements for Airbus group $C D F$ rate. This difference is evaluated at two points:

- Among all of the Airbus aircrafts, A340-500/600 has more weight distributed on each wheels. Because its weight is high and wheels number is low, that leads to high $C D F$ contribution among other aircrafts in Airbus group.

- Main gear arrangement for A-340-500/600 is triple dual tandems and total number of wheels for this aircraft is 12 . This aircraft's arrangement is regulated than other aircraft in Airbus group, and gross weight load is distributed upon a higher level of the pavement, so that causes to adjust the loading; also during aircraft movement in runway and taxiway, only two wheels lead to rutting in pavement. That this factor causes $C D F$ contribution for this aircraft in rigid and flexible pavement has not differed.

Fig. 1 also shows B777 - 300 ER has a most $C D F$ rate of flexible pavement for sample airport mixed traffic, but this rate is divided into half in rigid pavement. This difference was made by B777-300ER wheels arrangement, because this model has triple dual tandem, as all of 12 wheels are only in 4 path strip in the pavement surface. This arrangement is evaluated at two points:

- The tire contact area is only in 4 path strip on the pavement surface. This reason causes of increasing damage in a special section of pavement surface.

- In the design process by LEDFAA with assumed material modulus, thickness of Asphalt Concrete surface in flexible pavement is $127 \mathrm{~mm}$ and thickness of Portland Cement Concrete surface in rigid pavement is $443.6 \mathrm{~mm}$, therefore, rigid pavement's high thickness and rigidity cause damages rate for B777-300ER of flexible pavement to be more than that on rigid pavement. Also gross weight load distribution upon rigid pavement is on wide levels of pavement; and this factor causes to increasing $C D F$ rate for B - 777 - $300 \mathrm{ER}$ on flexible pavement.

In Fig. 3 the Airbus and Boeing group aircrafts weight and total wheels are categorized, by using this Figure we understand the effect of weight, total wheels and wheels arrangement on pavement damages.

Fig. 3 represents B747 - 400 ER to have more gross weight and individual wheel load than B777-300 ER, however compared to B777 - 300 ER with its linear arrangement, this aircraft proved to lead less damage because of its suitable wheels arrangement. Tire contact area on the pavement is only in 4 tapes of path on the pavement surface, this cause increased damage in a special section of pavement surface.

Fig. 3 also represents A380-800 and A380-800 F to have most gross weight in other aircrafts with any of them not to have a maximum $C D F$ rate. Therefore, mere gross weight cannot 
Tab. 1. Traffic Data and Design Assumption for Sample Airport

\begin{tabular}{|c|c|c|c|c|c|c|}
\hline $\begin{array}{l}\text { Aircraft } \\
\text { Model }\end{array}$ & $\begin{array}{c}\text { Gross } \\
\text { Weight (tons) }\end{array}$ & $\begin{array}{l}\text { Tire Pres- } \\
\text { sure (kpa) }\end{array}$ & $\begin{array}{c}\text { Annual } \\
\text { Departure }\end{array}$ & $\begin{array}{c}\text { Annual } \\
\text { Growth (\%) }\end{array}$ & Design Life & $\begin{array}{c}\text { Percent } \\
\text { Gross } \\
\text { Weight on } \\
\text { Gear }\end{array}$ \\
\hline B - $747-200$ & 377.84 & 1379 & 1200 & 5 & 20 & 95 \\
\hline B - $747-400$ & 395.98 & 1379 & 1200 & 5 & 20 & 95 \\
\hline $\begin{array}{l}\text { B - 747 - } \\
400 \text { ER }\end{array}$ & 414.12 & 1586 & 1200 & 5 & 20 & 95 \\
\hline $\begin{array}{l}\text { B - } 767 \text { - } \\
300 \text { ER }\end{array}$ & 185.52 & 1379 & 1200 & 5 & 20 & 47.5 \\
\hline $\begin{array}{l}\text { B - } 767 \text { - } \\
400 \text { ER }\end{array}$ & 204.57 & 1482 & 1200 & 5 & 20 & 47.5 \\
\hline B - $777-200$ & 243.58 & 1276 & 1200 & 5 & 20 & 47.5 \\
\hline $\begin{array}{l}\text { B - } 777- \\
200 \text { ER }\end{array}$ & 287.80 & 1482 & 1200 & 5 & 20 & 47.5 \\
\hline B - $777-300$ & 300.27 & 1482 & 1200 & 5 & 20 & 47.5 \\
\hline $\begin{array}{l}\text { B - } 777 \text { - } \\
300 \text { ER }\end{array}$ & 341.10 & 1503 & 1200 & 5 & 20 & 47.5 \\
\hline А300-600 & 170.09 & 1331 & 1200 & 5 & 20 & 47.5 \\
\hline $\begin{array}{c}\text { A300-600- } \\
\text { opt }\end{array}$ & 170.09 & 1110 & 1200 & 5 & 20 & 47.5 \\
\hline А330 & 212.73 & 1379 & 1200 & 5 & 20 & 47.5 \\
\hline $\begin{array}{l}A-340- \\
500 / 600\end{array}$ & 366.2 & 1572 & 1200 & 5 & 20 & 32.9 \\
\hline $\begin{array}{c}\text { A - } 340 \text { - } \\
500 / 600 \text { Belly }\end{array}$ & 366.2 & 1531 & 1200 & 5 & 20 & 29.3 \\
\hline A380 - 800 & 562 & 1338 & 1200 & 5 & 20 & 95.0 \\
\hline A380-800 F & 592 & 1358 & 1200 & 5 & 20 & 95.0 \\
\hline
\end{tabular}

Tab. 2. Design Results by LEDFAA Software for Rigid and Flexible Pavement

\begin{tabular}{|c|c|c|c|c|c|}
\hline \multicolumn{3}{|c|}{ Rigid } & \multicolumn{3}{|c|}{ Flexible } \\
\hline Layer Material & Thickness (mm) & $\begin{array}{c}\text { Modulus or } \\
R(\mathrm{MPa})\end{array}$ & Layer Material & Thickness (mm) & $\begin{array}{c}\text { Modulus or } \\
R(\mathrm{MPa})\end{array}$ \\
\hline PCC Surface & 443.6 & 4.83 & $\begin{array}{c}\text { P - } 401 \mathrm{AC} \\
\text { Surface }\end{array}$ & 127 & $1,378.95$ \\
\hline $\mathrm{P}-304 C T B$ & 152.4 & $3,447.38$ & P - 401 St (flex) & 203.2 & $2,757.90$ \\
\hline P-209 Cr Ag & 152.4 & 244.27 & P - 209 Cr Ag & 459.7 & 389.42 \\
\hline Subgrade & $k=38.38$ & 103.42 & Subgrade & $C B R=10$ & 103.42 \\
\hline
\end{tabular}




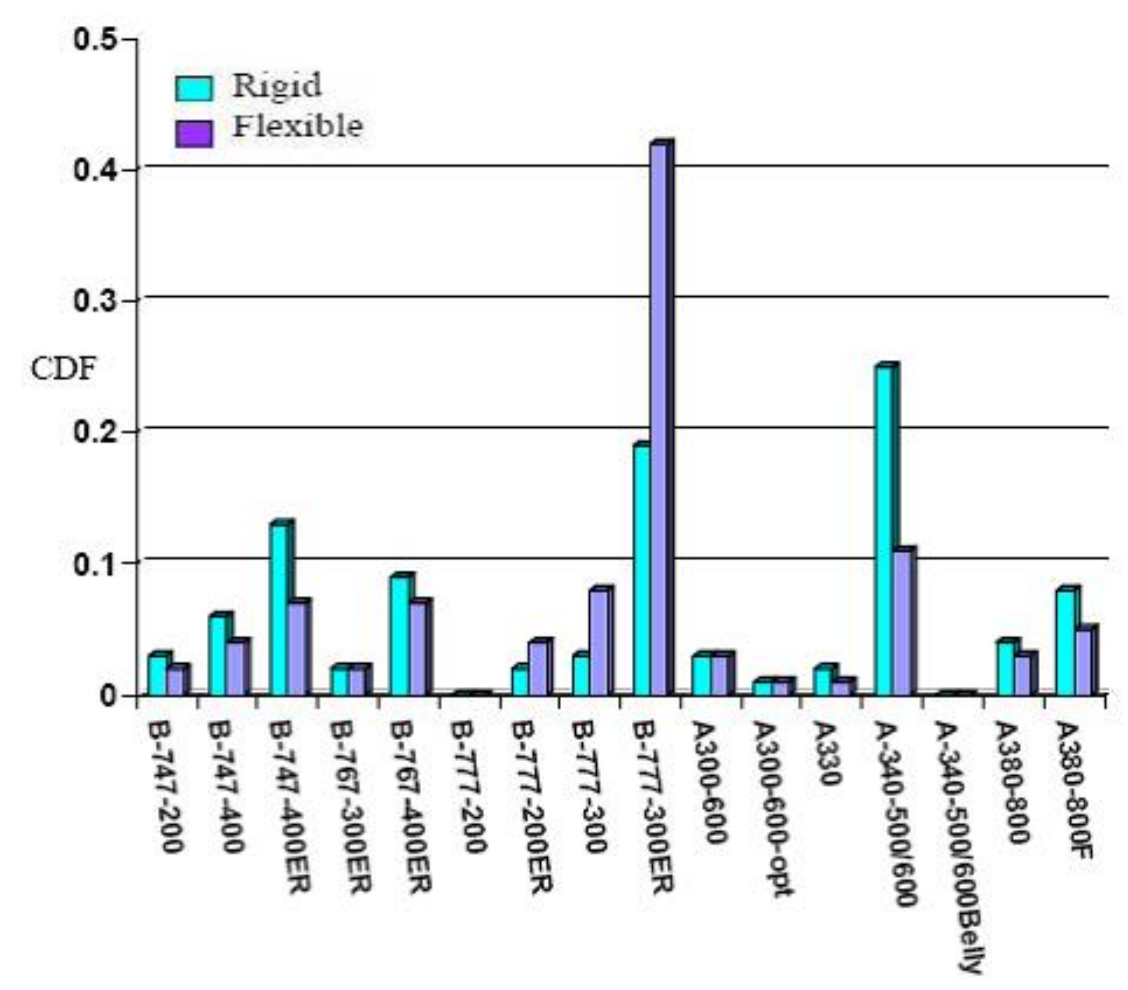

Fig. 2. Comparison $C D F$ Rate in Sample Airfield with Mixed Traffic

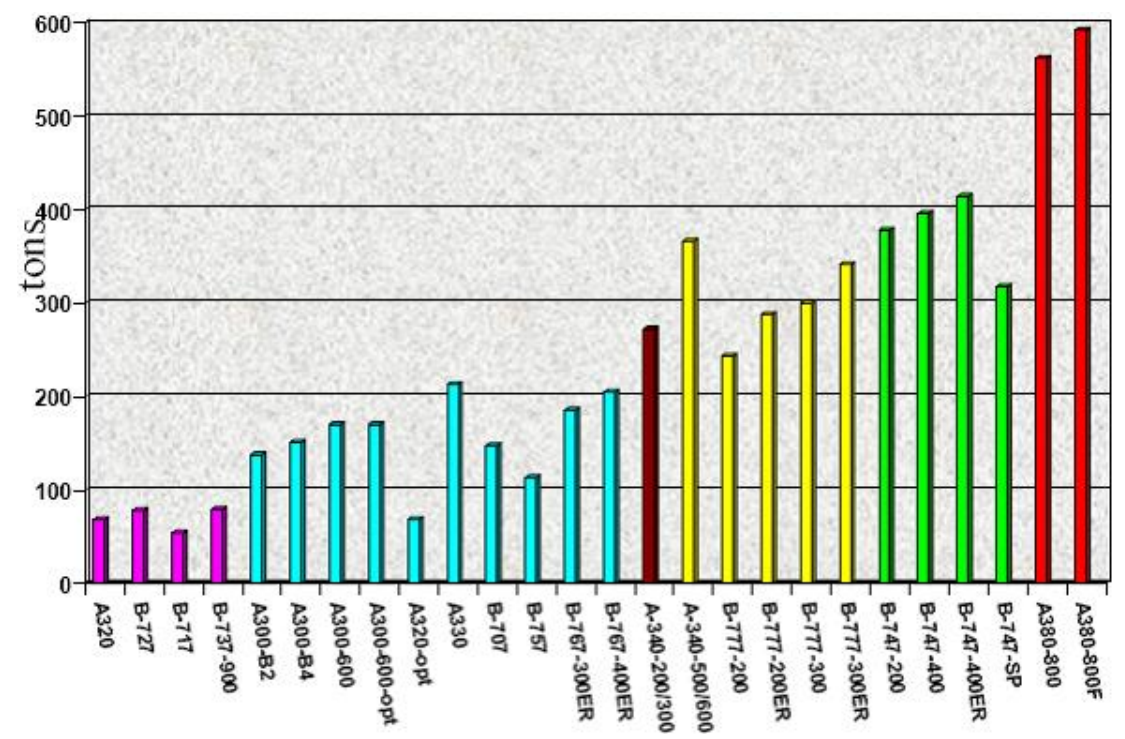

Fig. 3. Gross Weight and Total Wheels for Airbus and Boeing Aircraft in Mixed Traffic 
make effect with wheels arrangement type and total number of wheels as effective factors in the $C D F$ rate. Thus when we have aircrafts gross weight and number of wheels for aircrafts, capable to determine individual wheel load for Airbus and Boeing aircrafts, this work was done and shown in Fig. 4

Figs. 3 and 4 show the A380-800 with 20 wheels and 592 tons weight which is balanced and divided on its wheels, with each wheel supporting 29.6 tons. This number for A340 $500 / 600$ with 12 wheels is 30.5 tons, thus in comparing between weight and individual wheel load for these two aircrafts, we discovered the rate of load transferring in pavement by any wheels in A340-500/600 to be more than that in A380-800, which that is the lead to increase the $C D F$ rate for A340-500/600.

\section{Study of the Effects of Wheel Configuration and FAARFIELD software results}

To investigate wheel load interaction, three sets of axle configuration, i.e., single, tandem, and triad, was investigated. The stress distributions caused by the adjacent load in a tandem configuration is superimposed yielding a different stress distribution caused by adjacent wheel. Due to the close spacing between axles/wheels, the critical pavement responses under multiple loads are different from those under a single load. Even if the passage of each set of multiple loads is assumed to be one repetition, the damage caused by single axle would not be the same as that caused by tandem or triad axle. The analyses indicate that the primary response parameters of pavement caused by different load configurations were substantially different for each.

For example, B - 777 - 300 ER has Triple Dual Tandem (TDT) and its wheels arrangement shape leads to wheel loading in a thin width of pavement surface and have engendered failures such rutting and cracks and increasing rate intensity of making damage in flexible pavement. And when the thickness of asphalt concrete surface in flexible pavement is low, it causes increasing damage rate in this aircraft. Pavement application is load distribution upon a higher level of subgrade that is larger than levels of wheels bearing area. Load distribution is different in flexible and rigid pavement in the Layered Elastic Design method; this load distribution in rigid pavement is larger than flexible pavement. Therefore, we have a most $C D F$ rate in mixed traffic for flexible pavement.

In the rigid pavement, the $C D F$ rate for $A 340-500 / 600$ is more than all of the Airbus and Boeing aircrafts, because of aircraft gross weight distribution on wheels. Also for this model as shown in Fig. 4 (c), 66\% of weight supports by main gear and $33 \%$ of weight supports by nose gears. Also in Fig. 4 four aircrafts gear arrangement is shown.

Some Airbus and Boeing aircraft's main gear configuration are shown in Fig. 5. Certain airplanes with D or 2D belly gear (A340 series) are treated as two separate airplanes for design, a two-gear 2D airplane (wing gear), and a single-gear D or 2D airplane (body gear). For example, adding an A340 - 500 / 600 to the design list, automatically place the two airplanes for design in the list. In Fig. 5] 3D-Finite Element meshes for various gear configurations are shown.

All aircraft are grouped into one of the four categories shown in Fig. 6 Since the same 3D-FE mesh is used for all aircraft gears within a given category, the 3D-FE process needs to be called only once for each category, not once for each aircraft. Once the stress is computed for the first aircraft in the group, stresses for remaining aircraft are computed by backcalculation using the already decomposed stiffness matrix, a much less time consuming process [25].

Same as the previous section, 15 model aircraft which had a highest $C D F$ rate are chosen for mixed traffic in sample airport. Also annual departure in first year is assumed 1200, and percent annual growth is assumed 5\%. CDF diagram and distance from centerline for each aircraft on rigid and flexible pavements are shown in Fig. 7

According to Fig. 7, B-777-300 ER has the highest $C D F$ rate among other aircrafts, and this is the same for both flexible and rigid pavements. Also A340-500/600 has the second highest $C D F$ rate among other aircrafts in both flexible and rigid pavements.

Results from FAARFIELD software related to flexible pavement, show that these results are similar to LEDFAA software results, but there are visible difference in rigid pavement. Unlike the flexible pavement, B777-300 ER has the highest $C D F$ rate among other aircrafts. The reasons for this difference are discussed in the following:

- FAARFIELD implements both layered elastic based and three-dimensional finite element-based design procedures.

- Designs for new generation airplanes having 3D landing gears, such as the Boeing B777 and Airbus A380 series, were not covered by the previous design procedures. AC 150/5320 - 6E, in conjunction with FAARFIELD, provides the necessary information for thickness design when 3D and complex airplane gears are included in the airplane mix.

- Rigid design is the same flexible design except that $C D F$ is calculated using the horizontal edge stress at the bottom of the PCC layer

\section{Conclusions}

The programs LEDFAA and FAARFIELD, recently introduced into pavement design practice, have many features in common but differ in some respects. According to Fig. 2, in the rigid pavement, the $C D F$ rate for $\mathrm{A} 340-500 / 600$ is more than all of the Airbus and Boeing aircrafts. It is because of aircraft gross weight distribution on wheels and for any wheel having 30.5 tons. Also for this model $66 \%$ of the weight is supported by main gear and $33 \%$ of weight by nose gears. On the other hand, According to Fig.7, B - 777 - 300 ER has the highest $C D F$ rate among other aircrafts, and this is same for both flexible and 


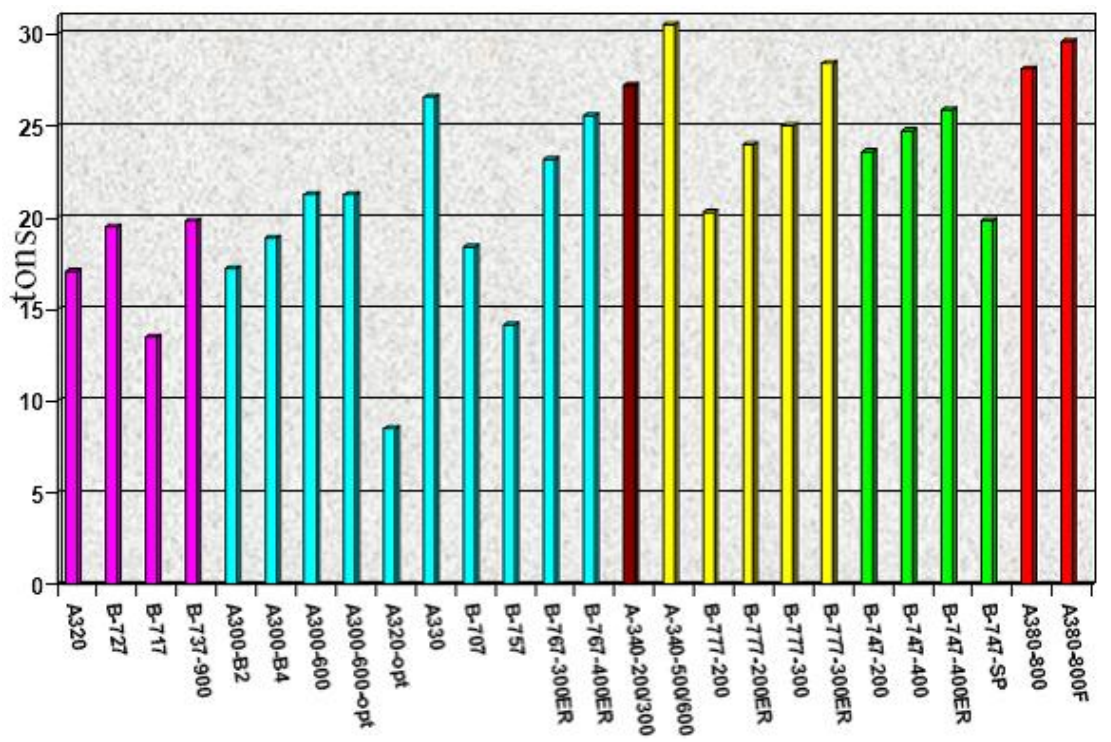

Fig. 4. Individual Wheel Load for Airbus and Boeing Aircraft in Mixed Traffic

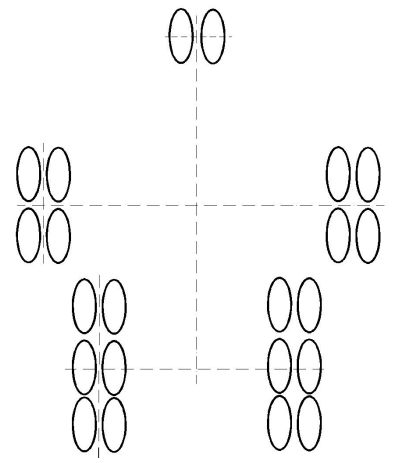

(a) 2D/3D2 - Two Dual Wheels in Tandem Main Gear/Three Dual Wheels in Tandem Body Gear with Dual wheel Nose Gear, Airbus A380<smiles>C1CCC2CCCCC2C1</smiles>

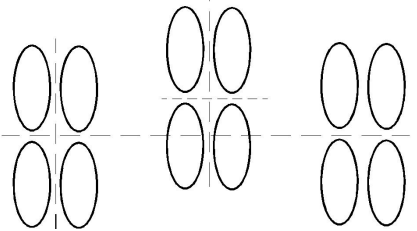

(c) 2D/2D1 Two Dual Wheels in Tandem Main Gear/Two Dual Wheels in Tandem Body Gear with Dual Wheel Nose Gear, Airbus A340 - 500 / 600

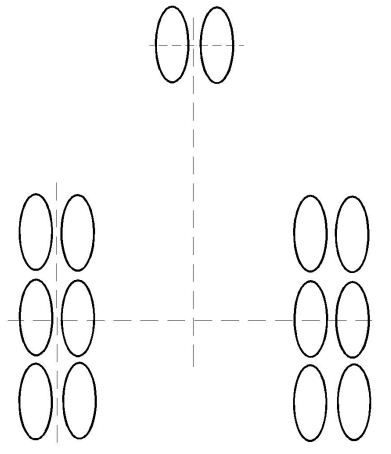

(b) 3D - Three Dual Wheels in Tandem Main Gear with Dual Wheel Nose Gear, Boeing B - 777<smiles>[GeH3]</smiles>

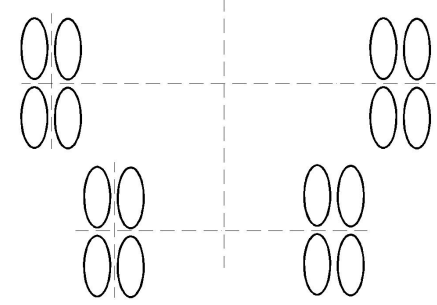

(d) 2D/2D2 - Two Dual Wheels in Tandem Main Gear/Two Dual Wheels in Tandem Body Gear with Dual Wheel Nose Gear, Boeing B - 747

Fig. 5. Wheels Number and Geometric Arrangement for Some Airbus and Boeing Aircrafts 23. 

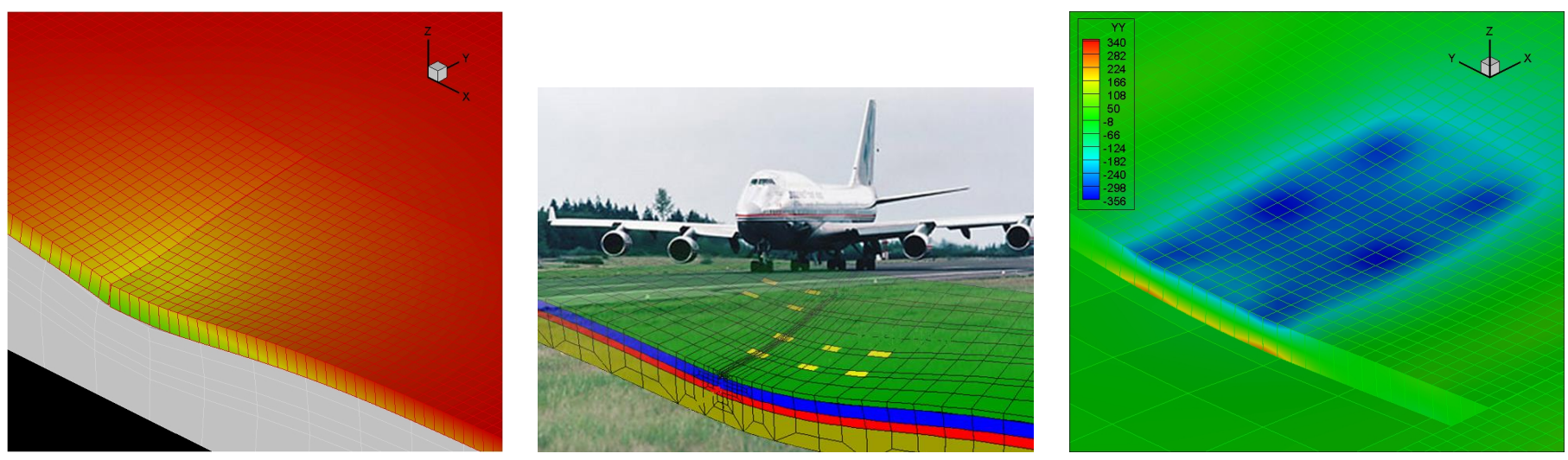

Fig. 6. 3D-FE Meshes for Various Gear Configurations [24].

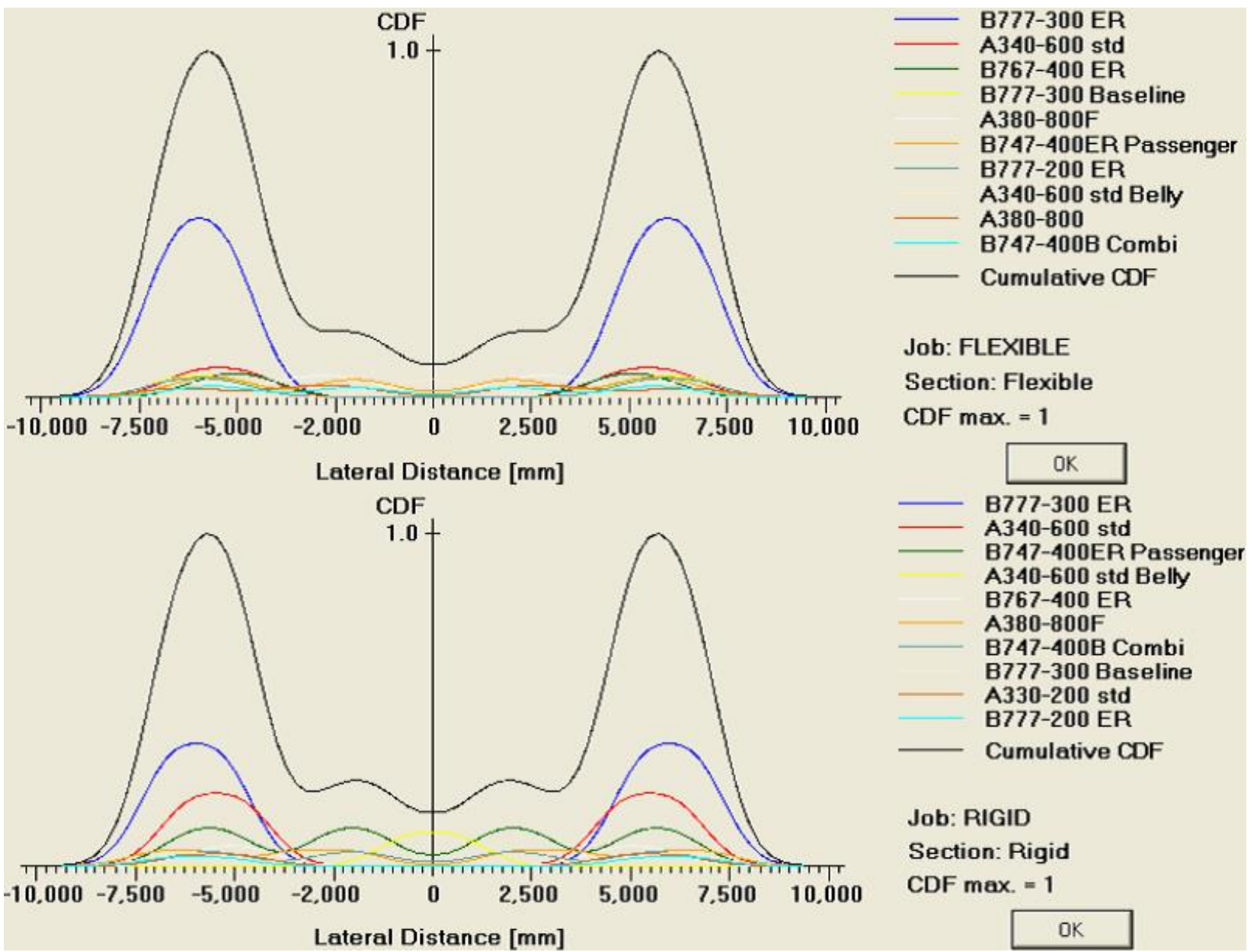

Fig. 7. FAARFIELD $C D F$ Rate Diagram for Aircraft Mixed Traffic Flexible and Rigid pavement

rigid pavements. A340-500/600 has the second highest $C D F$ rate among other aircrafts in both flexible and rigid pavements. This difference shows that LEDFAA software focuses on individual wheel load, and mainly aircrafts with the highest individual wheel load have a high $C D F$ rate as shown in Fig. 2. Also, as shown in previous, FAARFIELD software implements both layered elastic based and three-dimensional finite element-based design procedures developed by the Federal Aviation Administration (FAA) for new and overlay design of flexible and rigid pavements and 3D-FE mesh is used for all aircraft gears.

Many research documents use of 3D finite element applica- tion for predicting mechanical behavior and pavement performance subjected to various traffic factors. Different axle configuration, tire imprint areas and inflation pressure are investigated here to analyze the considerable impact on pavement damage initiation from fatigue and permanent deformation point of view. In this study, rigid and flexible pavement modeling is done using FAA software. Models in this paper are evaluated by LEDFAA and FAARFIELD software. For more analysis in complex gear configuration, we need to use FE method to determining stress and strain on all pavement layers. In the other hand, a case study on airport pavement design needs to full scale test to validating 
FE result, it usually needs many facilities and testing tools, also full scale study is very expensive. It is hoped this happening in the near future.

The present research has an effective role in the Airport Pavement Management System as it cognizes about any aircraft distribution in $C D F$ rate. It helps designers to manage the airfield pavement and to increase the pavement life. Obviously for generalization of the results there should be more study on aircraft group with different condition until this numeral study be nearer to full scale tests.

Advisory Circular AC 150/5320 - 16 in airport pavement design for the Boeing 777 has been canceled and the layered elastic based design procedures implemented in LEDFAA for that advisory circular have been incorporated in Change 3 of AC 150/5320 - 6D Airport Pavement Design and Evaluation. Version 1.2 of LEDFAA has also been canceled and is replaced by version 1.3. Version 1.3 is approved for use in all applications where version 1.2 is applicable and may also be used for designs in which the aircraft mix does not include a Boeing 777, or other aircraft with six-wheel landing gears.

\section{References}

1 Navneet Garg, Introduction to FAA's national airport pavement test facility (NAPTF), In: 3th International Conference on APT; Madrid, Spain, September 30, 2008.

2 Willis M, Johnson D, Sukumaran B, Three-Dimensional Finite Element Analyses of Flexible Airport Pavement for the Next Generation of Aircrafts, Airfield and Highway Pavement, In: Al-Qadi I L (ed.), Airfield and Highway Pavement: Meeting Today's Challenges with Emerging Technologies, American Society of Civil Engineers; Atlanta, Georgia, United States, 2006, pp. 13-24.

3 Gopalakrishnan K, Thompson M R, Rutting Study of NAPTF Flexible Pavement Test Sections, Airfield Pavements Specialty Conference 2003, In: Karakouzian M (ed.), Airfield Pavements: Challenges and New Technologies, American Society of Civil Engineers; Las Vegas, Nevada, United States, 2004, pp. 73-11.

4 Gopalakrishnan K, Evaluation of accelerated deterioration in NAPTF flexible test pavement, Journal of Zhejiang university SCIENCE A, 9, (2008), 1157-1166, DOI 10.1631/jzus.A0720153

5 LEDFAA User's Manual, Federal Aviation Administration; USA, 2004.

6 Izydor K, Brill D R, Hayhoe G F, FAARFIELD - NEW FAA Airport Thickness Design Software, FAA Worldwide Airport Technology Transfer Conference, In:; Atlantic City, New Jersey, USA, April 2007.

7 Airport Pavement Design for the Boeing 777 Airplane, Federal Aviation Administration; USA, 2004.

8 Thompson M R, Garg N, Wheel Load Interaction: Critical Airport Pavement Responses, In: Federal Aviation Administration Airport Technology Transfer Conference; Atlantic City, NJ, 1999.

9 Hayhoe G, Traffic Testing Results from the FAA's National Airport Pavement Test Facility, In: 2nd International Conference on Accelerated Pavement Testing; University of Minnesota, Minneapolis, MN, 2004.

10 Tutumluer E, In Tai Kim, Permanent Deformation Behavior of Airport Pavement Base and Subbase Courses, University of Illinois, UrbanaChampaign; Urbana-Champaign USA, November 9, 200.

11 Rodney N. Joel, FAA Rigid Pavement and Tools Design Philosophy, In: Northwest Region Airports Conference; USA, 2006.

12 Hao W H, Al-Qadi I L, Effect of High Aircraft Tire Pressure on Flexible
Pavements: Near-Surface Damage, In: FAA Worldwide Airport Technology Transfer Conference; Atlantic City, 2010.

13 Adil Godiwalla, Dev R. Pokhrel, Airport Engineering, In: Houston Airport System Pavement Seminar; Houston Texas, Sept. 14, 2011.

14 Mojarrad H, hree Dimensional Nonlinear Finite Element Analysis of Airport Pavements, Thesis, North Carolina State University, 2011.

15 Shafabakhsh G A, Kashi E, A Numerical Study Effect of Aircraft's Main Gear Configuration on Airport Runway Damages, Technics Technologies Education Management TTEM journal, 7, (2012), 811-819.

16 Fi I, Szentpéteri I, A Mechanistic-Empirical Approach for Asphalt Overlay Design of Asphalt Pavement Structures, Periodica Polytechnica Civil Engineering, 58, (2008), 55-62, DOI 10.3311/PPci.7408

17 Tutumluer E, Thompson MR, Anisotropic Modeling of Granular Bases In Flexible Pavements, Transportation Research Record, 1557, (1997), 18-26, DOI 10.3141/1577-03

18 Bartha G, Temperature Changes in Asphalt Pavements in Summer, Periodica Polytechnica Civil Engineering, 46, (2002), 43-52.

19 Hayhoe G F, Correspondence between ICAO and overload criteria and cumulative damage factor Calculations, In: 2010 FAA worldwide airport technology transfer conference; Atlantic City, New Jersey, USA, 2010.

20 Brill D R, Review of 10 Years of Concrete Airport Pavement Studies at the NAPTF and Next 10 Year Plan, In: 2nd International Conference on Best Practices for Concrete Pavements; Florianopolis, Brazil, 2011.

21 Guo E H, Concrete Pavement Strength and Beam Flexural Strength, In: 2010 FAA Worldwide Airport Technology Transfer Conference; New Jersey, USA, 2010.

22 Gopalakrishnan K, Thompson M R, Comparative Effect of B777 and B747 Trafficking on Elastic Layer Moduli of NAPTF Flexible Pavements, In: 2004 FAA Worldwide Airport Technology Transfer Conference; Atlantic City, NJ, USA, 2004.

23 Standard Naming Convention for Aircraft Landing Gear Configurations, U.S. department of transportation Federal Aviation Administration; USA, 2005.

24 Kawa I, Brill D, Hayhoe G F, FAARFIELD - New FAA Airport Thickness Design Software, In: AA Worldwide Airport Technology Transfer Conference; New Jersey, USA, 2007.

25 Brill D, Izydor K, Hayhoe G F, Development of FAARFIELD airport pavement design software, In: Transportation Systems 2004 Workshop; USA, 2004. 